\title{
The Migration of Air into the Aorta from a Pneumothorax in a Patient with a Penetrating Injury of the Aorta
}

\author{
Youichi Yanagawa, MD, PhD ${ }^{1 *}$, Akihiko Kondo, MD², Toshihiko Yoshizawa, MD ${ }^{1}$, Kei Jitsuiki, MD \\ Takahito Miyake, $\mathrm{MD}^{3}$, Hiromichi Ohsaka, MD, PhD', Manabu Sugita, MD, $\mathrm{PhD}^{2}$ \\ ${ }^{1}$ Department of Acute Critical Care Medicine, Shizuoka Hospital, Juntendo University, Izunokuni City, Shizuoka Prefecture, Japan \\ ${ }^{2}$ Department of Emergency and Critical Care Medicine, Nerima Hospital, Juntendo University, Nerima ku, Tokyo, Japan \\ ${ }^{3}$ Department of Orthopedics, Shizuoka Hospital, Juntendo University, Izunokuni City, Shizuoka Prefecture, Japan
}

\begin{abstract}
A tree fell on the back of a 77-year-old male. A postmortem computed tomographic pan scan revealed systemic air embolism, multiple rib fractures with a penetrating injury to the aorta, pneumohemothorax, and air in the aorta. A massive amount of air entered the site of a penetrating injury of the aorta. This unique case adds one more cause to the list of documented etiologies of air in the aorta.

Copyright $\odot 2016$ Science International Corp.
\end{abstract}

\section{Key words}

Penetrating injury of aorta $\bullet$ Rib fracture $\cdot$ Pneumothorax

\section{Introduction}

Migration of air into the aorta is rare. We report a rare case of a patient in whom a penetrating aortic injury caused by broken ribs, led to the migration of air into the aorta from a pneumothorax.

\section{Case Presentation}

A tree fell on the back of a 77-year-old male when he was cutting down trees. When emergency technicians (EMTs) reached him, he was in a state of

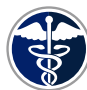

Fax +1 2037853552

E-Mail: aorta@scienceinternational.org

http://aorta.scienceinternational.org

\author{
(c) 2016 AORTA \\ Published by Science International Corp. \\ ISSN 2325-4637 \\ Accessible online at: \\ http://aorta.scienceinternational.org
}

cardiopulmonary arrest. The initial rhythm was asystole. Tracheal intubation, the insertion of a chest drain into the left thorax and the infusion of fluid and adrenaline were performed by the EMTs and an emergency physician. After his transfer to Shizuoka Hospital, Juntendo University, a monitor revealed that he remained asystolic in a state of cardiopulmonary arrest. The findings of a blood gas analysis $\left(\mathrm{FiO}_{2}\right.$ 1.0) on arrival were $\mathrm{pH}: 6.671, \mathrm{PCO}_{2}: 44.6 \mathrm{mmHg}_{1} \mathrm{PO}_{2}: 48.7$ $\mathrm{mmHg} \mathrm{HCO}_{3}^{-}: 4.9 \mathrm{mmol} / \mathrm{l}$, base excess: $-26.1 \mathrm{mmol} / \mathrm{l}$ and hemoglobin: $1.9 \mathrm{~g} / \mathrm{dl}$. Additional right thoracostomy was performed but a return of spontaneous circulation was not obtained. A postmortem computed tomographic (CT) pan scan performed 90 minutes after the patient's collapse revealed systemic air embolism, multiple rib fractures with a penetrating injury to the aorta, lung contusion, pneumohemothorax, pneumomediastinum, air in the aorta and a lumbar fracture (Figure 1). The cause of death was unstable circulation due to massive hemorrhage from an aortic injury and air embolism, and respiratory failure due to lung contusion and pneumohemothorax.

\section{Discussion}

The main causes of migration of air into the aorta

\footnotetext{
* Corresponding Author:

Youichi Yanagawa, MD, PhD

Department of Acute Critical Care Medicine, Shizuoka Hospital Juntendo University

1129 Nagaoka, Izunokuni City, Shizuoka 410-2295, Japan

Tel.: +8155948 3111; Fax: +8155948 3187; E-Mail: yyanaga@juntendo.ac.jp
} 

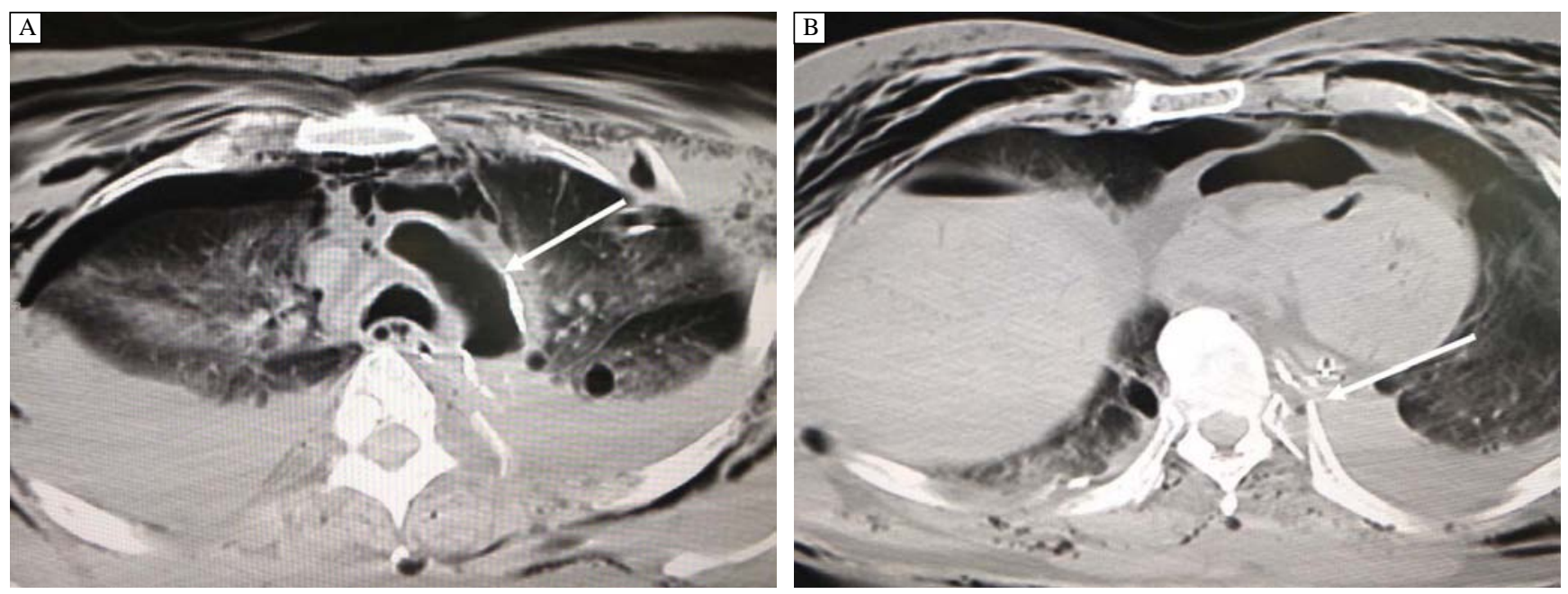

Figure 1. The postmortem computed tomographic (CT) pan scan. Panel A. Lung contusion, pneumohemothorax, pneumomediastinum and air in the aortic arch. Panel B. CT revealed multiple rib fractures with a penetrating injury to the aorta.

are iatrogenic, these include cardiac or aortic surgery, arterial endovascular management or transthoracic lung biopsy [1-5]. In rare cases, the suicidal connection of a peripheral venous catheter with oxygen gas has resulted in the migration of air into aorta [6]. In patients with decompression sickness, CT can demonstrate intra-arterial gas [7]. In the present case, a massive amount of air ventilated with positive pressure in a patient with pneumothorax, entered the site of a penetrating injury of the aorta (caused by rib fractures), which resulted in the aorta being filled with air. To the best of our knowledge, this is the first case to describe the introduction of air into the aorta by such a mechanism. The air in the aorta may have been the result of a massive hemorrhage and the introduction of air after the death of the patient as a result of no circulation and the presence of a hole in the aorta. However, distinguishing premortem from postmortem phenomena is difficult. Lung trauma involving laceration of air passages, lung parenchyma, and blood vessels may result in direct communication of these structures. Systemic air or gas embolism occurs when air or gas enters the pulmonary venous system as a result of a positive gradient caused by a low pulmonary venous pressure. Dedouit et al. [8] showed that a small amount of air in the ascending aorta due to a paradoxical embolism through patent foramen ovale or across the pulmonary capillary bed created tension pneumothorax. The present case also had lung contusion, and the gas in the aorta may have been produced by the paradoxical embolism. However, the amount of gas in the aorta in our case was massive, and we noted no gas at all in the left side of the heart. These findings therefore make it unlikely that the gas was produced by a paradoxical embolism.

This unique case adds one more cause to the list of documented etiologies of air in the aorta. The induction of microbubbles by arterial endovascular management, which can be detected by ultrasound, can be asymptomatic [9]. However, in one report, the detection of the air in the aorta by radiological studies indicated systemic air embolization, which tended to be associated with a poor outcome, similar to that which was observed in our case [5].

In the present case, a massive amount of air ventilated with positive pressure in a patient with pneumothorax, entered the site of a penetrating injury of the aorta (caused by rib fractures), which resulted in the aorta being filled with air. This unique case adds one more cause to the list of documented etiologies of air in the aorta.

\section{Conflict of Interest}

The authors have no conflict of interest relevant to this publication.

\section{Comment on this Article or Ask a Question}




\section{References}

1. Nakamura $Y$, Tagusari $O$, Seike $Y$, Ito $Y$. Persistence of intra-aortic air after circulatory arrest. J Vasc Surg. 2010;52:1061. DOI: 10.1016/j.jvs.2009.10.111

2. Kutlu R, Nisanoğlu V. Air within the aneurysm sac following endovascular management of abdominal aortic aneurysm in a patient with acute pancreatitis. Diagn Interv Radiol. 2009;15:153-156. PMID: 19517388

3. Pando Sandoval A, Ariza Prota MA, García Clemente $M$, Prieto $A$, Fole Vázquez $D$, Casán P. Air embolism: a complication of computed tomography-guided transthoracic needle biopsy. Respirol Case Rep. 2015;3:48-50. DOI: 10.1002/rcr2.97

4. El-Sayed Ahmed MM, Aftab M, de la Cruz KI, Delgado RM 3rd, Mallidi HR. Circular air-filled space in the aortic knob: a rare radiologic finding. Tex Heart Inst J. 2014;41:560-561. DOI: 10.14503/THIJ-13-

\section{6}

5. van der Zee MP, Koene BM, Mariani MA. Fatal air embolism during cardiopulmonary bypass: analysis of an incident and prevention measures. Interact Cardiovasc Thorac Surg. 2014;19:875-877. DOI: 10.1093/icvts/ ivu242

6. Laurent PE, Coulange $M$, Desfeux J, Bartoli C, Coquart B, Vidal V, et al. Post-mortem computed tomography in a case of suicide by air embolism. Diagn Interv Imaging. 2013;94:460-462. DOI: 10.1016/j. diii.2013.01.014

7. Laurent $\mathrm{PE}$, Coulange $\mathrm{M}$, Mancini J, Bartoli C, Desfeux J, Piercecchi-Marti MD, et al. Postmortem CT appearance of gas collections in fatal diving accidents. AJR Am J Roentgenol. 2014;203:468-475. DOI: 10.2214/AJR.13.12063

8. Dedouit F, Otal P, Loubes-Lacroix F, Rousseau $H$, Costagliola $R$, Telmon $N$, et al.
Post-traumatic venous and systemic air embolism associated with spinal epidural emphysema: multi-slice computed tomography diagnosis. Forensic Sci Int. 2006;158:190-4.

9. Pagel PS, Klinger JE, Colwell EM, Rashid ZA. "Air" in the aortic arch after cannulation for cardiopulmonary bypass: devastating complication or benign explanation? J Cardiothorac Vasc Anesth. 2015;29:542-544. DOI: 10.1053/j.jvca.2014.08.017

Cite this article as: Yanagawa $Y$, Kondo A, Yoshizawa T, Jitsuiki, K Miyake T, Ohsaka $H$, Sugita M. Migration of air into the aorta from a pneumothorax in a patient with a penetrating injury of the aorta. AORTA (Stamford). 2016; 4(3):102-104. DOI: http://dx.doi. org/10.12945/j.aorta.2016.16.006

\section{EDITOR'S QUESTIONS}

\section{How do you know that this patient did not simply exsanguinate, with the aortic air entering post- mortem?}

In my experience, including previous successful cases [1] (all others ultimately died and were not reported on), patients in whom the aorta has been penetrated by broken ribs due to blunt trauma do not immediately enter cardiac arrest. Witnesses saw the patient in the present case collapse, and he was already in cardiac arrest when the emergency technicians checked him. l, therefore, hypothesize that this patient suffered from some other trauma that resulted in immediate cardiac arrest.

2. How about pericardial embolism through an atrial septal defect (ASD)? How about penetrating lung injury, which under positive pressure forces air into the pulmonary veins and subsequently into the aorta, often with fatal results (diagram in Elefteriades JA, et al. House Officer's Guide to ICU Care, 3rd Edition, 2013)? Please comment.

Because he underwent regular medical check-ups and his history did not indicate any cardiac problems, including murmur, I believe that the likelihood of an ASD is low. To our knowledge, no previous papers have reported such a large amount of aortic air due to lung injury, with high positive pressure air force.

3. How often are postmortem computed tomography (CT) scans performed in Japan? (They have shown that aortic dissection accounts for up to $7.5 \%$ of all lethal out-of-hospital cardiac arrests.)

The frequency of postmortem CT varies by medical institute in Japan; however, our hospital tries to perform whole-body CT for all patients who die of sudden cardiac arrest.

\section{References}

1. Yanagawa Y, Kaneko N, Hagiwara A, Kimura T, Isoda S. Delayed sudden cardiac arrest induced by aortic injury with a posterior fracture of the left rib. Gen Thorac Cardiovasc Surg. 2008;56:91-92. DOI: 10.1007/ s11748-007-0186-7 